\title{
An immersive virtual environment for Phantom Limb Pain rehabilitation
}

Link to publication record in Manchester Research Explorer

\section{Citation for published version (APA):}

Pettifer, S., Howard, T., Blundell, B., Edwards, D., \& Lieberman, I. (2012). An immersive virtual environment for Phantom Limb Pain rehabilitation. In GRAPP 2012 IVAPP 2012 - Proceedings of the International Conference on Computer Graphics Theory and Applications and International Conference on Information Visualization Theory and Applications/GRAPP IVAPP - Proc. Int. Conf. Comput. Graph. Theory Appl. Int. Conf. Inf. Vis. Theory Appl. (pp. 426-433)

\section{Published in:}

GRAPP 2012 IVAPP 2012 - Proceedings of the International Conference on Computer Graphics Theory and Applications and International Conference on Information Visualization Theory and Applications|GRAPP IVAPP Proc. Int. Conf. Comput. Graph. Theory Appl. Int. Conf. Inf. Vis. Theory Appl.

\section{Citing this paper}

Please note that where the full-text provided on Manchester Research Explorer is the Author Accepted Manuscript or Proof version this may differ from the final Published version. If citing, it is advised that you check and use the publisher's definitive version.

\section{General rights}

Copyright and moral rights for the publications made accessible in the Research Explorer are retained by the authors and/or other copyright owners and it is a condition of accessing publications that users recognise and abide by the legal requirements associated with these rights.

\section{Takedown policy}

If you believe that this document breaches copyright please refer to the University of Manchester's Takedown Procedures [http://man.ac.uk/04Y6Bo] or contact uml.scholarlycommunications@manchester.ac.uk providing relevant details, so we can investigate your claim.

\section{OPEN ACCESS}




\title{
AN IMMERSIVE VIRTUAL ENVIRONMENT FOR PHANTOM LIMB PAIN REHABILITATION
}

\author{
Steve Pettifer ${ }^{1}$, Toby Howard ${ }^{1}$, Ben Blundell ${ }^{1}$, David Edwards ${ }^{1}$ and Ilan Lieberman ${ }^{2}$ \\ ${ }^{1}$ School of Computer Science, The University of Manchester, Oxford Road, Manchester, M13 9PL, United Kingdom. \\ ${ }^{2}$ University Hospital of South Manchester NHS Foundation Trust, Wythenshawe Hospital, Southmoor Road, Manchester, \\ M23 9LT, United Kingdom. \\ \{steve.pettifer, toby.howard\}@manchester.ac.uk
}

\begin{abstract}
Keywords: Virtual Environments : Phantom Limb Pain
Abstract: Phantom Limb Pain is a debilitating condition that affects a significant percentage of patients after loss of an arm or leg. These patients experience chronic pain and other unpleasant sensations in the missing limb, and the pain resists treatment. Previous research has demonstrated that pain levels can be reduced in some patients when they are immersed in a virtual environment that presents a 3D computer graphics visualisation of their missing limb, the movements of which are controlled by sensors attached to the remaining limb. In this paper we describe a novel approach to the implementation of such a system, using the Kinect game device for limb motion tracking, in conjunction with wireless motion sensors worn by the patient. We present some preliminary, but very encouraging, results based on an informal trial with a patient.
\end{abstract}

\section{INTRODUCTION}

We present an interactive wireless computer graphics virtual environment (VE) designed to form part of a treatment regime for amputee patients who suffer from the debilitating effects of Phantom Limb Pain. We implement the VE using the Kinect motion tracking device, wireless inertial sensors, OpenGL, and the Cinder $\mathrm{C}++$ library. In this paper we begin with an introduction to the condition of Phantom Limb Pain, and then present an overview our our prototype VE, presenting some preliminary results and observations from an informal trial with an amputee patient.

\section{BACKGROUND}

Following the loss of a limb, whether by surgery or trauma, it is common for amputees to report the sensation that their missing limb remains attached to their body (one of the earliest reports being Mitchell, 1872). Sometimes under volitional control, while in other cases frozen in a specific position, these socalled 'phantom limbs' often present such a vivid illusion that it takes conscious effort for the amputee to adjust to not using the missing limb as part of their everyday lives (Jensen and Nikolajsen, 1994). Many amputees experience some form of Phantom Limb
Pain (PLP), and although studies vary in their methods of classifying PLP, it is generally accepted that between $60 \%$ and $85 \%$ of amputees suffer from some degree of PLP (Kooijman et al., 2000; Desmond and MacLachlan, 2006; Ephraim et al., 2005; Ehde et al., 2000; Black et al., 2009).

The manifestation of PLP varies according to the individual, including feelings of clenching, burning, stabbing, severe itching and 'electric shocks', which are often associated with a sense that the phantom limb is contorted or misshapen in some way (Flor, 2002). Severe PLP (which occurs in around $25 \%$ of sufferers) has been shown to cause societal withdrawal for extended periods (Sherman et al., 1984), and amputees with PLP are less likely to use a prosthetic limb, which often restricts their normal activities (Dolezal et al., 1998), and they are prone to depression (Murray, 2005). According to the former National Amputee Statistical Database (now Limbless Statistics (2011)), each year in the UK there are 5,500 new referrals to prosthetic service centres, and 62,000 prosthesis users in total (NASDAB, 2002). The number of amputees worldwide is not reliably known, but studies in individual countries suggest a figure well in the millions (for example, Zeigler-Graham et al. (2008) report 1.7 million amputees in the USA alone).

It was originally thought that PLP was caused by nerve and tissue damage at the site of the amputation, 
and was therefore neuropathic pain, much the same as that caused by a burn or a cut. However PLP has proved resistant to the traditional range of pharmaceutical (e.g. Bone et al., 2002), surgical, and psychological pain management techniques (Kooijman et al., 2000). Coupled with the realisation that children born with missing limbs (where the problem is congenital rather than caused by trauma) may also suffer from PLP, this led to a hypothesis that the brain is in some sense 'hard-wired' to expect signals from four limbs, and that PLP results from a mismatch between this mental template and the signals being generated by the body itself (Flor et al., 1995; Borsook et al., 1998; McCabe et al., 2005).

\subsection{Visual therapy}

In 1996, psychologist V. K. Ramachandran devised an experiment using a 'mirror box' (Ramachandran and Rogers-Ramachandran, 1996) that allowed amputees to view a reflection of their anatomical limb in the visual space occupied by their phantom limb. He reported that the mirror box induced vivid sensations of movements originating from patients' phantom limbs, and in some cases relieved their PLP. Since then, others have experimented with alternative visual therapies such as the use of video (e.g. Giraux and Sirigu, 2003) or transcranial direct current stimulation (e.g. Soler et al., 2010) with comparable results.

Hypothesising that interactive visual therapies may work in similar ways to Ramachandran's box, around 2006 a number of research groups independently began investigating the use of synthetic computer graphics and virtual environments as a means of reproducing the positive effects of the mirror box, but without its physical limitations. MacLachlan's group developed an 'augmented mirror box' system in which a data-glove worn on the amputee's remaining anatomical limb was used to track hand movement and finger flexion (Desmond et al., 2006). This was used to control the movement of a synthetic representation of their phantom limb which was displayed on a flat screen that replaced the mirror box's mirror. The limb could be customised in detail to reflect any perceived distortions or contortions experienced by the user. Of the three participants in the study, two reported an intensification of their phantom experience, one reported gaining increased control over their phantom fingers, and one reported a reduction in their phantom pain. Cole et al. (2009) took a different approach, instrumenting the stump of the affected limb itself, and tracking its movement in order to control the virtual representation. From a cohort of seven upper limb and seven lower limb amputees, five subjects in each group reported some control over the movement of their phantom limb, and reported reductions in their PLP.

Our own previous work (Murray et al., 2006b, 2010, 2005, 2006b,a, 2007b,a) like MacLachlan's system, tracked the movement of the anatomical limb using a data-glove, transposing this motion to the computer-generated image of a virtual limb. Unlike MacLachlan, our system was a fully immersive environment, presented to the user via a tracked, headmounted display. In a small-scale trial, five participants whose PLP had resisted all other forms of treatment used our system on a weekly basis; four reported tangible reduction in their pain levels; two found they gained some control over their phantom limb's position, being able to manoeuvre it into a more comfortable state; and one found that they were even able to exercise some control over the stump of their amputated limb, which had previously been paralysed for over twelve years.

In what, for a clinical application, would be considered very small-scale trials, all three approaches demonstrated some success in allowing some (but notably, not all) of the participants to gain a degree of agency over their phantom limb and a measurable reduction in their pain levels. Given such small studies, it is clearly premature to make any profound claims about the effectiveness of the therapies. However, at the same time, it is difficult to ignore the potential of this approach as a non-invasive mechanism for reducing the considerable suffering of millions of amputees.

\subsection{The potential of virtual environments for treating PLP}

Two recent reviews of the use of virtual reality for pain control cautiously conclude that virtual environment 'distraction may be a useful tool for clinicians who work with a variety of pain problems' (Malloy and Milling, 2010) and that 'VR [Virtual Reality] is emerging as both a viable first-line intervention and as an adjunctive therapy to pharmacologic agents' (Mahrer and Gold, 2009). A further systematic review, which includes the use of mirror therapy for the treatment of Chronic Regional Pain Syndrome (a phenomenon thought to have similar causes to PLP (Sato et al., 2010)) finds that there is value in such an approach for the treatment of upper limb pain (Ezendam et al., 2009). It must be noted that none of these reviews specifically address the use of virtual reality as a therapy for PLP: Mahrer and Gold and Malloy et al. examine pain caused by physical trauma such as burns or surgery, whereas Ezendam et al. examine 
only the reduction in pain as a result of the use of a physical mirror box. We hypothesise, however, that since visual therapies can be shown to improve PLP, and that synthetic computer graphics can be used to create illusions that reduce pain, the virtual environment approach to PLP reduction is a worthwhile avenue of research.

All three studies emphasise the need for further work to better understand these effects. Mahrer et al. highlight the need for 'greater scientific rigor, increased sample sizes, sound methodology, and increased attention to individual user characteristics' (Mahrer and Gold, 2009) in future studies. Meeting such criteria using the systems described previously, however, is likely to present a significant practical challenge: all three systems were built using bespoke hardware and software, making them difficult to replicate in order to scale up to the kind of large scale trials necessary to clinically validate their use as effective therapies. In our own case it rapidly became impossible to source replacement parts for the specialist components as they developed faults (suppliers of virtual reality equipment are notoriously transient), and the only existing installation of our system became unusable.

Since these initial trials, however, there have been dramatic advances in computer graphics and related technologies: wearable displays, unencumbered tracking devices and powerful 3D graphics engines are now available as off-the-shelf consumer goods for PCs, games consoles and home entertainment systems. Although these devices are in some cases of lower quality than their specialist counterparts, because they are designed for general consumer use they are more robust, cheaper and more easily available. Driven by the demands of the computer games and entertainment market, it seems likely that the quality of these devices is only set to improve, and that their future availability is essentially guaranteed. For example, several groups (e.g., Calderwood et al., 2009; Lee, 2008; Scherfgen and Herpers, 2009; Sko and Gardner, 2009) have implemented virtual environments using the Nintendo Wii (Nintendo Wii, 2011).

With the aim of producing a system that could easily be replicated in order to support large-scale clinical trials, we embarked upon a project to reproduce our previous experimental setup using only consumer-grade hardware. The remainder of this paper describes this system, which we call 'PLP2'.

\section{SYSTEM DESIGN AND IMPLEMENTATION}

Our previous system used electromagnetic tracking, with wired sensors attached the patient's head and anatomical limb. While providing reasonably accurate absolute six degrees-of-freedom (DOF) tracking and thus needing no calibration as such, these devices required cumbersome wiring, and were also sensitive to metal objects and electrical cabling which distorted the tracking space, making finding a location to carry out experiments difficult. Equipping the patient with the sensors required specialist training, and patients needed careful supervision during their sessions to avoid becoming entangled in the numerous cables. With the exception of the video feed, our new system requires no cables and is not sensitive to metal/electricity in the environment.

The PLP2 system engages the patient in gameplay, as shown in Figure 1. There are two games, both of which aim simply to give the patient a purpose to engage with the environment in a way that causes them to move their virtual limb. In both scenarios, the patient remains standing but is able to turn around and has space to move a few steps in any direction. In the ball-following game, the patient uses their virtual limb to track the position of a ball, which moves randomly around their position while remaining 'within reach'). In the tic-tac-toe game, the 'game grid' is represented by a $3 \times 3$ array of spheres, where the patient indicates their move by touching the relevant sphere. In each game the patient's task is to use their intact limb for interaction. The patient wears an ordinary baseball cap, instrumented with lightweight sensors for tracking head movement, sending data wirelessly to the control computer. The patient's anatomically intact limb is tracked using the Kinect motion tracking device (Xbox 360 Kinect, 2011), and the tracked movements are used to control a computer graphical representation of the missing limb in the virtual environment. The patient views the VE immersively using a Vuzix VR920 headset (Vuzix, 2011). The Vuzix was chosen for its reasonably high resolution screen (monoscopic, with two 640x480 panels), its lightweight build and the addition of a rubber 'eyeshield' that blocks external light, creating a more immersive experience.

Figure 2 shows the software architecture of the system, which uses only cross-platform components (though our experiments have been conducted using Mac OS X 10.6). The Cinder graphics library (Cinder, 2011) provides basic functionality and cross-platform graphics support. OpenNI (OpenNI, 2011) and the NITE Middleware (NITE, 2011) allows the Kinect to 


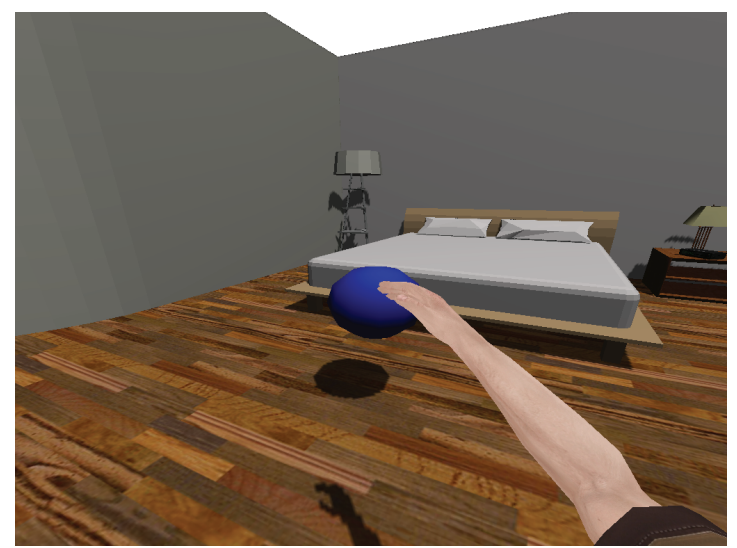

(a)

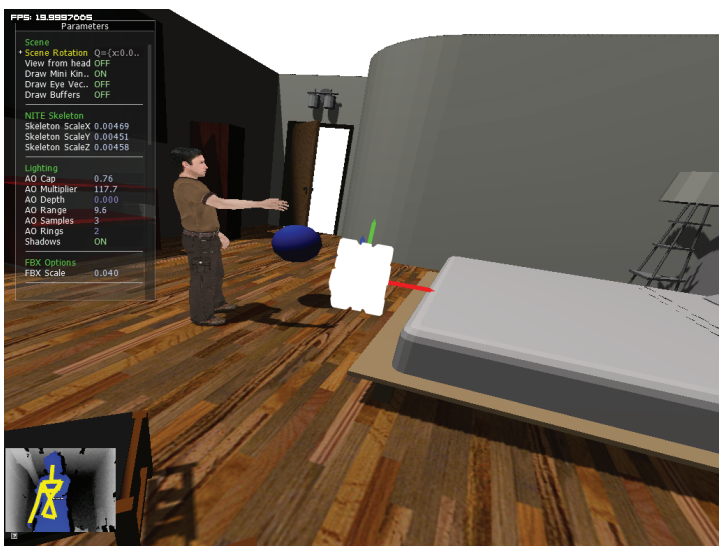

(b)

Figure 1: Screenshots of the system in use. Panel (a) shows the virtual environment as seen by the participant playing the 'ball following' game. Panel (b) shows the same environment as seen by the operator, with the environment's control display in the top left of the image, and the Kinect's skeleton tracking window at bottom left.

be linked to Cinder in order to detect and track participants. NITE provides basic information on the position and orientation of a set number of limbs and joints for each detected person. A capture pose is required by the OpenNI middleware in order to estimate the lengths of the limbs within the system. This must take place before any skeleton tracking can begin. This calibration step is performed per-patient, and our prototype implementation requires an anatomically complete image, which for an amputee patient may involve an assistant temporarily holding a 'dummy' limb (constructed from cardboard) in place.

To determine the orientation of the patient's head, a six-DOF Inertial Measurement Unit from Sparkfun (Sparkfun, 2011) is linked to an XBee IEEE Standard 802.15.4 radio (XBee, 2011) run by a lithium polymer battery. The unit is attached to the patient's baseball cap. Orientation is computed using Kalman filtering (Kálmán, 1960; Welch, 2009) and an initial rest point. Raw data from the three gyroscopes and three accelerometers are sent wirelessly over the XBee wireless link to the computer running the simulation.

With the orientation of the head from the gyroscope and the orientation of the body and the position of the joints from the Kinect, a simple 3D skinned representation of the participant can be created in 3D. Models are generated from FBX files (FBX, 2011) which support the generation of bones, clusters and associated weights needed to deform a model correctly.

\section{RESULTS}

Our goal has been to build a cheap, portable, nonintrusive system for experiments in use of virtual environments for PLP rehabilitation, with the aim of replicating - and then, through larger-scale trials bettering the results observed in previous VE/PLP experiments which used more expensive and fragile equipment. To this end, we have built a prototype system that uses mostly 'off the shelf' cheap, easily available and replaceable components, and designed tasks within the virtual environment that work within the constraints of the hardware. From a purely 'virtual reality technology' perspective, we believe the results are very encouraging; for the overall cost of the system (an order of magnitude cheaper than our previous technology), the virtual environment is comparable in quality, and because of the wireless tracking, using the system is considerably simpler and more comfortable for the patient. The system's current limitations (awkward initial calibration, cumulative drift in the gyroscope data, and lack of finger flexion or hand rotation tracking), we believe can be addressed in future developments.

Perhaps more positive than the technological results, however, have been the system's effects during a preliminary, and highly informal, trial with one amputee patient. The trial was intended to give us basic feedback on the behaviour and 'feel' of the system from a patient's point of view, rather than to invoke any therapeutic effect. The patient had, five years previously, undertaken trials with our first VR PLP system, and had experienced reduction in pain lasting for several days after each use. In the PLP2 trial, 


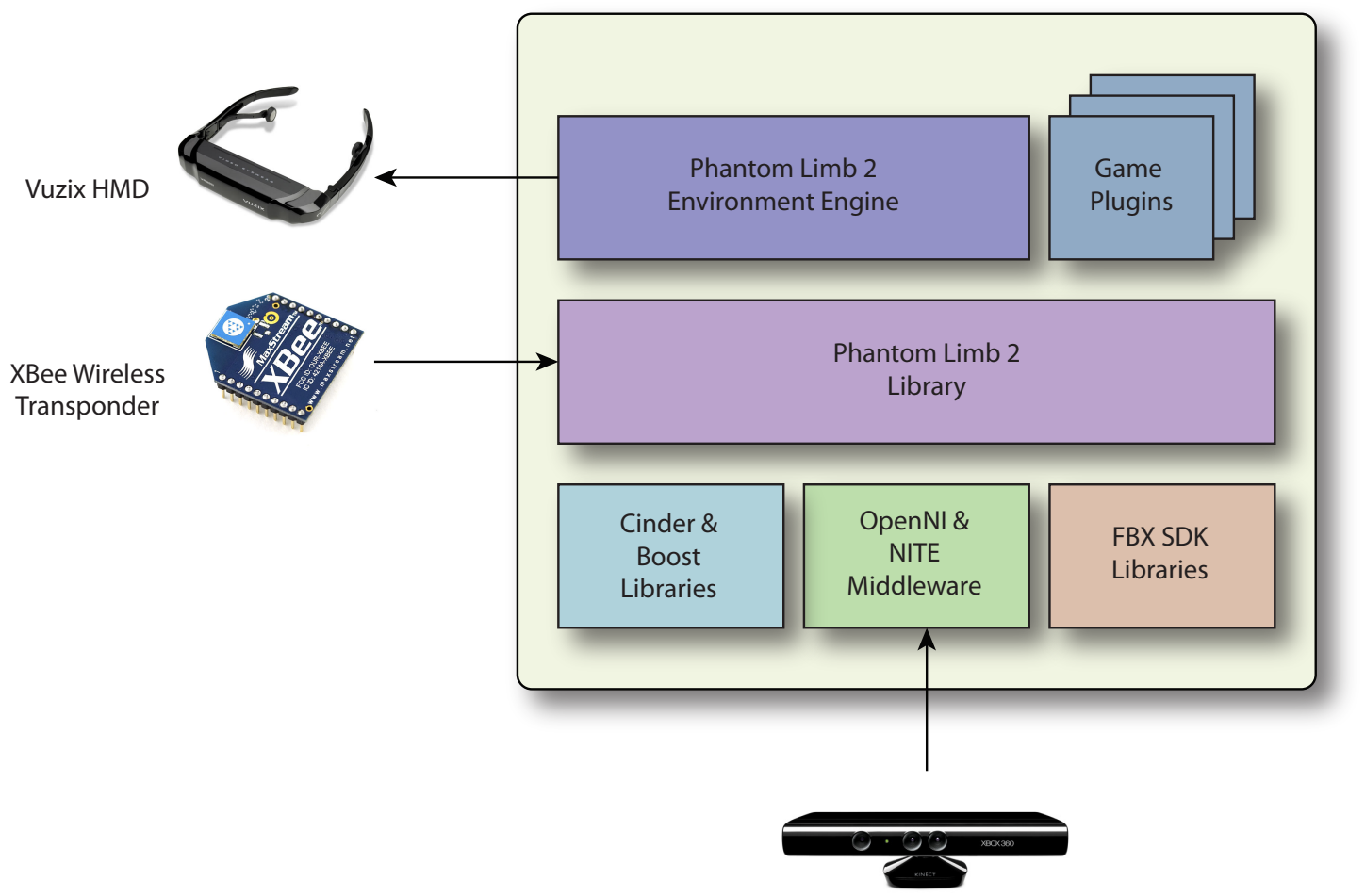

Kinect $(\mathrm{tm})$ Motion Tracker

Figure 2: Architecture of the PLP2 system, showing the relationship between the main software components and the hardware devices.

which lasted three hours, the patient was introduced to the system and after 15 minutes of free acclimatisation to the virtual environment and the limb tracking, was asked to play the games. On arrival, the patient reported their pain level as 8 (on the Numerical Rating Scale of 10 , with $0=$ no pain and $10=$ worst). After 30 minutes using the PLP2 system, the patient reported his pain level had reduced to 2.5. A short video illustrating the informal trial is available at http://aig.cs.man.ac.uk/research/plp2.

\section{CONCLUSIONS AND FUTURE WORK}

Our first conclusion is simply that it is possible to design and build a VE system for exploring PLP using primarily 'off the shelf' components. Our second is that, though taking into account all possible technological and psychological issues, the number of variables to control for in future trials of this technology is daunting, it is nevertheless interesting to observe that the three approaches to VR PLP therapy described in Section 2 all had broadly comparable levels of suc- cess in reducing pain; and this in spite of them taking radically different approaches to tracking and rendering (indeed, they appear to share no common technology). Even in our informal short trial reported in Section 4 - which again shares no common technology with our previous experimental setup - the patient reported a non-trivial therapeutic effect. We note that the various studies cited here of parameters relating to VR pain reduction all use VR as a source of distraction from physical/neuropathic pain. It has been suggested that the between-patient variability in response to visual therapy is related more to the patient's susceptibility to the virtual visual feedback than to physical factors (Mercier and Sirigu, 2009). Because of the substantial variation in the techniques and parameters that have been explored in this space with comparable results, we speculate further that whatever the causes of PLP, the therapeutic effect of VR is as much an effect of the process of gaining agency over a phantom limb using a virtual representation, as it is of any specific feature or parameter of the virtual environment.

There remain many interesting questions to be addressed, which include: how important is the dimensionality of the virtual environment? In our previous 
system, the patient saw a true stereo view, from left and right images in the head-mounted display's respective eye-screens; in PLP2, we currently present the patient with a 2D view of the VE. This leads to the general issue of photorealism - what roles, if any, do the quality of the image, the frame-rate, and the graphical realism play in any reduction of pain felt by the patient? Some authors (such as (Hoffman et al., 2006)) believe that display quality is an important factor. From our experience we remain unconvinced that this is necessarily true.

Our research into the use of virtual environments for PLP rehabilitation is ongoing, and our immediate plans are to improve PLP2 to enable us to address the issues of inaccurate tracking and tracking drift, to engineer a system which is more robust, and to use the improved system for a set of formal clinic trials with our project partners, where we will conduct experiments to assess the contributions that factors such as dimensionality and 'realism' make to therapeutic value.

\section{REFERENCES}

Black, L. M., Persons, R. K., and Jamieson, B. (2009). Clinical inquiries. What is the best way to manage phantom limb pain? J Fam Pract, 58:155-158.

Bone, M., Critchley, P., and Buggy, D. J. (2002). Gabapentin in postamputation phantom limb pain: a randomized, double-blind, placebo-controlled, crossover study. Reg Anesth Pain Med, 27:481-486.

Borsook, D., Becerra, L., Fishman, S., Edwards, A., Jennings, C. L., Stojanovic, M., Papinicolas, L., Ramachandran, V. S., Gonzalez, R. G., and Breiter, H. (1998). Acute plasticity in the human somatosensory cortex following amputation. Neuroreport, 9:10131017.

Calderwood, M. D., Kelly, J., McNamara, T. P., and Bodenheimer, B. (2009). Adding head tracking to desktop virtual reality with the wii remote as an aid to spatial cognition. In Proceedings of the 6th Symposium on Applied Perception in Graphics and Visualization, APGV '09, pages 125-125, New York, NY, USA. ACM

Cinder (2011). libcinder.org.

Cole, J., Crowle, S., Austwick, G., and Slater, D. H. (2009). Exploratory findings with virtual reality for phantom limb pain; from stump motion to agency and analgesia. Disabil Rehabil, 31:846-854.

Desmond, D. M. and MacLachlan, M. (2006). Affective distress and amputation-related pain among older men with long-term, traumatic limb amputations. J Pain Symptom Manage, 31:362-368.

Desmond, D. M., O’Neill, K., Paor, A. D., McDarby, G., and MacLachlan, M. (2006). Augmenting the reality of phantom limbs: Three case studies using an augmented mirror box procedure. Journal of Prosthetics and Orthotics, 18(3):74-79.

Dolezal, J. M., Vernick, S. H., Khan, N., Lutz, D., and Tyndall, C. (1998). Factors associated with use and nonuse of an ak prosthesis in a rural, southern, geriatric population. Int J Rehabil Health, 4(4):245-251.

Ehde, D. M., Czerniecki, J. M., Smith, D. G., Campbell, K. M., Edwards, W. T., Jensen, M. P., and Robinson, L. R. (2000). Chronic phantom sensations, phantom pain, residual limb pain, and other regional pain after lower limb amputation. Arch Phys Med Rehabil, 81:1039-1044.

Ephraim, P. L., Wegener, S. T., MacKenzie, E. J., Dillingham, T. R., and Pezzin, L. E. (2005). Phantom pain, residual limb pain, and back pain in amputees: results of a national survey. Arch Phys Med Rehabil, 86:1910-1919.

Ezendam, D., Bongers, R. M., and Jannink, M. J. (2009). Systematic review of the effectiveness of mirror therapy in upper extremity function. Disabil Rehabil, $31: 2135-2149$.

FBX (2011). usa.autodesk.com.

Flor, H. (2002). Phantom-limb pain: characteristics, causes, and treatment. Lancet Neurol, 1:182-189.

Flor, H., Elbert, T., Knecht, S., Wienbruch, C., Pantev, C., Birbaumer, N., Larbig, W., and Taub, E. (1995). Phantom-limb pain as a perceptual correlate of cortical reorganization following arm amputation. Nature, 375:482-484.

Giraux, P. and Sirigu, A. (2003). Illusory movements of the paralyzed limb restore motor cortex activity. $\mathrm{Neu}$ roimage, 20 Suppl 1:S107-111.

Hoffman, H. G., Seibel, E. J., Richards, T. L., Furness, T. A., Patterson, D. R., and Sharar, S. R. (2006). Virtual reality helmet display quality influences the magnitude of virtual reality analgesia. J Pain, 7:843-850.

Jensen, T. S. and Nikolajsen, L. (1994). Phantom limb pain and other phenomena after amputation. Churchill Livingstone.

Kálmán, R. E. (1960). A new approach to linear filtering and prediction problems. Transactions of the ASMEJournal of Basic Engineering, (D):35-45.

Kooijman, C. M., Dijkstra, P. U., Geertzen, J. H., Elzinga, A., and van der Schans, C. P. (2000). Phantom pain and phantom sensations in upper limb amputees: an epidemiological study. Pain, 87:33-41.

Lee, J. C. (2008). Hacking the nintendo wii remote. IEEE Pervasive Computing, 7:39-45.

Limbless Statistics (2011). www.limbless-statistics.org.

Mahrer, N. E. and Gold, J. I. (2009). The use of virtual reality for pain control: a review. Curr Pain Headache Rep, 13:100-109.

Malloy, K. M. and Milling, L. S. (2010). The effectiveness of virtual reality distraction for pain reduction: a systematic review. Clin Psychol Rev, 30:1011-1018.

McCabe, C. S., Haigh, R. C., Halligan, P. W., and Blake, D. R. (2005). Simulating sensorymotor incongruence in healthy volunteers: implications for a cortical model of pain. Rheumatology, 44(4):509-516. 
Mercier, C. and Sirigu, A. (2009). Training with virtual visual feedback to alleviate phantom limb pain. $\mathrm{Neu}$ rorehabil Neural Repair, 23:587-594.

Mitchell, S. W. (1872). Injuries of nerves and their consequences. J. B. Lippincott. Digitised at www.archive.org/details/injuriesofnerves00mitcuoft.

Murray, C. D. (2005). The social meanings of prosthesis use. J Health Psychol, 3(10):425-441.

Murray, C. D., Patchick, E., Pettifer, S., and Howard, T. (2006a). Investigating the efficacy of a virtual mirror box in treating phantom limb pain in a sample of chronic sufferers. In Sharkey, P., Brooks, T., and Cobb, S., editors, Proceedings of The 6th International Conference on Disability, Virtual Reality and Associated Technologies, pages 167-174, Esbjerg, Denmark. ISBN 704998653.

Murray, C. D., Patchick, E., Pettifer, S., Howard, T., Kalkarni, J., and Bamford, C. (2007a). Investigating the efficacy of a virtual mirror box in treating phantom limb pain in a sample of chronic sufferers. International Journal of Disability and Human Development, 5(3):227-234.

Murray, C. D., Pettifer, S., Caillette, F., Patchick, E., and Howard, T. (2005). Immersive virtual reality as a rehabilitative technology for phantom limb experience. Proc IWVR 2005 4th Int Workshop Virtual Rehabi, pages 144-151.

Murray, C. D., Pettifer, S., Caillette, F., Patchick, E., and Howard, T. (2006b). Immersive virtual reality as a rehabilitative technology for phantom limb experience: A protocol. CyberPsychol Behav, 2(9):167-170.

Murray, C. D., Pettifer, S., Howard, T., E. Patchick, F. C., and Murray, J. (2010). Virtual solutions to phantom problems: Using immersive virtual reality to treat phantom limb pain. In Murray, C., editor, Amputation, Prosthesis and Phantom Limb Pain, pages 175-197. Springer. ISBN 0387874615.

Murray, C. D., Pettifer, S., Howard, T., Patchick, E., Kalkarni, J., and Bamford, C. (2007b). The treatment of phantom limb pain using immersive virtual reality: three case studies. Disability and Rehabilitation, 29(18):1465-1469. ISSN 1464-5165 (electronic) 0963-8288 (paper).

NASDAB (2002). National Amputation Statistical Database Annual Report. The Department of Health, Social Services and Public Safety (UK).

Nintendo Wii (2011). www.nintendo.com/wii.

NITE (2011). www.primesense.com.

OpenNI (2011). www.openni.org.

Ramachandran, V. S. and Rogers-Ramachandran, D. (1996). Synaesthesia in phantom limbs induced with mirrors. Proc Biol Sci, (341):377-386.

Sato, K., Fukumori, S., Matsusaki, T., Maruo, T., Ishikawa, S., Nishie, H., Takata, K., Mizuhara, H., Mizobuchi, S., Nakatsuka, H., Matsumi, M., Gofuku, A., Yokoyama, M., and Morita, K. (2010). Nonimmersive virtual reality mirror visual feedback therapy and its application for the treatment of complex regional pain syndrome: an open-label pilot study. Pain Med, 11:622-629.
Scherfgen, D. and Herpers, R. (2009). 3d tracking using multiple nintendo wii remotes: a simple consumer hardware tracking approach. In Proceedings of the 2009 Conference on Future Play on @ GDC Canada, Future Play '09, pages 31-32, New York, NY, USA. ACM.

Sherman, R. A., Sherman, C. J., and Parker, L. (1984). Chronic phantom and stump pain among american veterans: results of a survey. Pain, 18:83-89.

Sko, T. and Gardner, H. (2009). The wiimote with multiple sensor bars: creating an affordable, virtual reality controller. In Proceedings of the 10th International Conference NZ Chapter of the ACM's Special Interest Group on Human-Computer Interaction, CHINZ '09, pages 41-44, New York, NY, USA. ACM.

Soler, M. D., Kumru, H., Pelayo, R., Vidal, J., Tormos, J. M., Fregni, F., Navarro, X., and Pascual-Leone, A. (2010). Effectiveness of transcranial direct current stimulation and visual illusion on neuropathic pain in spinal cord injury. Brain, 133:2565-2577.

Sparkfun (2011). www.sparkfun.com.

Vuzix (2011). www.vuzix.com/consumer/products_vr920.html.

Welch, G. F. (2009). History: The use of the kalman filter for human motion tracking in virtual reality. Presence: Teleoper. Virtual Environ., 18:72-91.

XBee (2011). www.digi.com/xbee.

Xbox 360 Kinect (2011). www.xbox.com/kinect.

Zeigler-Graham, K., MacKenzie, E. J., L.Ephraim, P., Travison, T. G., and Brookmeyer, R. (2008). Estimating the prevalence of limb loss in the United States - 2005 to 2050. Archives of Physical Medicine and Rehabilitation, 89:422-429. 